RELATOS DE CASO

\title{
PSEUDOMIXOMA PERITONEAL: ABORDAGEM CIRÚRGICA EM DOIS CASOS
}

\section{PSEUDOMYXOMA PERITONEI: A SURGICAL APPROACH IN TWO CASES}

\author{
Olívio Louro Costa, TCBC-ES ${ }^{1}$ \\ Vitor Buaiz ${ }^{1}$ \\ Carlos Sandoval Gonçalves ${ }^{1}$
}

\section{INTRODUÇÃO}

Os pseudomixomas peritoneais são tumores raros, caracterizados por ascite mucinosa, envolvendo a superfície peritoneal, omento e alças intestinais e comumente estão associados a tumores benignos ou malignos do apêndice ou ovários ${ }^{1,2}$. O apêndice é o local de origem na maioria dos $\operatorname{casos}^{3}$. Encontram-se dois tumores em 10.000 laparotomias e a expectativa é que um cirurgião-geral encontre dois casos em toda a sua carreira ${ }^{4}$. Elias e Sabourin ${ }^{4}$ admitem que existem duas formas clínicas da doença, que são a "adenomatose mucinosa peritoneal difusa" e a "carcinomatose peritoneal mucinosa", sendo que o prognóstico, a abordagem cirúrgica e outros recursos terapêuticos são diferentes nas duas circunstâncias. O propósito deste estudo é analisar a conduta cirúrgica em dois pacientes com pseudomixoma, operados durante o mês de maio de 2000

\section{RELATO DOS CASOS}

\section{CASO 1}

Homem, 80 anos, referia há dois anos dor e edema dos membros inferiores e sentia aumento progressivo do volume do abdome. Fora internado em outro hospital, onde se submeteu a uma paracentese com retirada de um litro de líquido ascítico. Quando da internação, o paciente estava caquético, normocorado e apresentava o abdome globoso, com circulação colateral evidente. Uma paracentese revelou líquido ascítico de consistência gelatinosa e com grumos de coloração amarelada. Também apresentava lesões de pele e tinha o diagnóstico de hanseníase. Uma laparoscopia confirmou a ascite gelatinosa, sendo retira- dos $2.000 \mathrm{ml}$ de líquido. Não foram observadas as vísceras e nem foi possível a biopsia, em vista da abundância do material gelatinoso. Com o diagnóstico provável de pseudomixoma, optou-se pela laparotomia, quando foram retirados cerca de dez litros de líquido ascítico com grumos de coloração amarelada. Havia uma cápsula que revestia todas as vísceras, impedindo a visualização das mesmas. Esperava-se massa apendicular, mas encontrou-se aspecto tumoral de flanco esquerdo, com orifício que drenava material gelatinoso, cuja biopsia revelou adenocarcinoma mucossecretor. Em vista de que o material era muito espesso para a colocação dos drenos habituais, optou-se por uma peritoneostomia de cinco centímetros, que foi realizada no quadrante superior esquerdo do abdome, com sutura do peritônio à pele (Figura 1). Por esta peritoneostomia foram realizadas lavagens diárias da cavidade até a regressão da loja. Não houve infecção e o paciente teve alta com pequena drenagem coletada por bolsa de colostomia. Tem sido acompanhado em ambulatório e seis meses após a operação, está bem, com trânsito intestinal normal e com drenagem mínima pela fístula.

\section{CASO 2}

Masculino, 72 anos, internado no Serviço de Gastroenterologia com relato de aumento de volume do abdome há um ano e dor nos últimos oito meses além de pirose retroesternal. $\mathrm{O}$ abdome era globoso, com circulação colateral e não se conseguia palpar vísceras. Endoscopia digestiva alta revelou compressão extrínseca da parede gástrica. Exame ultra-sonográfico confirmou ascite volumosa, de consistência espessa e septos delgados. O fígado apresentava apagamento da trama vascular, mas a vesícula, as vias biliares, o baço e os rins pareciam normais. Uma co-

\section{Professores do Centro Biomédico da Universidade Federal do Espírito Santo (UFES).}

Recebido em 17/05/2001

Aceito para publicação em 12/03/2002

Trabalho realizado nos Serviços de Clínica Cirúrgica e de Gastroenterologia do Hospital Universitário Cassiano Antonio de Moraes (HUCAM), da Universidade Federal do Espírito Santo (UFES) 


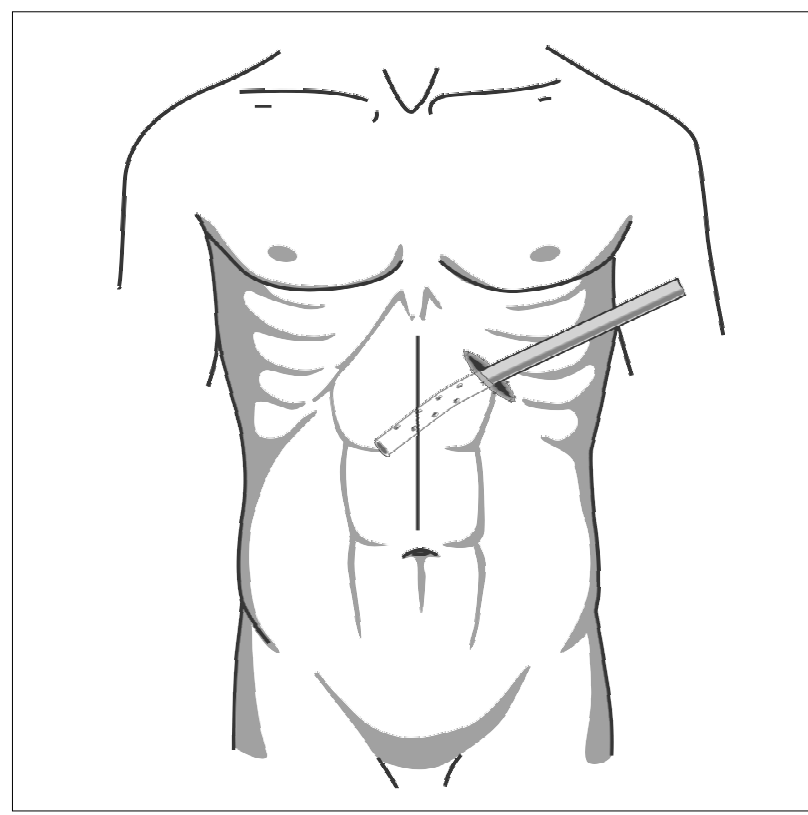

Figura 1. Modelo da peritoneostomia de cinco centímetros, para lavagem peritoneal.

lonoscopia não trouxe esclarecimentos. Realizada laparoscopia, encontrou-se líquido ascítico grumoso e bloqueio das alças por encapsulamento. Foi feita biopsia de peritônio, cujo resultado histopatológico revelou adenocarcinoma mucossecretor bem diferenciado. Em vista do resultado e considerando a impossibilidade de qualquer ressecção cirúrgica, optou-se pela peritoneostomia, com cerca de cinco centímetros, suturando-se o peritônio à pele. Houve drenagem de seis litros de secreção gelatinosa e foi feita a lavagem da cavidade com 18 litros de solução fisiológica. A lavagem da cavidade continuou, sempre com drenagem abundante de material grumoso, até que a aderência do peritônio à cápsula tivesse ocorrido e a drenagem cedido. Pequena drenagem sempre persistiu, coletada por bolsa de colostomia, mas o paciente teve alta, levando vida normal nos seis meses subseqüentes à cirurgia.

\section{DISCUSSÃO}

A doença é rara e poucos cirurgiões têm alguma experiência em relação à conduta cirúrgica no trato dos pacientes, quando se surpreendem com o primeiro caso, com uma ascite volumosa, de natureza mucinosa, cujo esvaziamento exige laparotomia. No primeiro paciente foi feita a laparotomia e havia dez litros de material mucinoso e grumoso. Uma carapaça recobria todas as alças e não era possível dissecá-las para tentar localizar a origem do tumor, ainda que houvesse um orifício no flanco esquerdo que se comunicava com loja mais profunda. Parecia necessária uma drenagem eficiente, para evitar reintervenções sucessivas de esvaziamento. Optou-se pela peritoneostomia porque esta abertura permitiria a lavagem diária da cavidade até a aderência da cápsula ao peritônio parietal. Como a loja estava delimitada, admitiu-se que o risco de infecção seria minimizado pela lavagem diária da cavidade. De fato assim ocorreu e o paciente sobrevive há mais de seis meses, com um mínimo de drenagem pela peritoneostomia. No segundo caso, a laparoscopia já permitiu a mesma compreensão do problema, ou seja, havia um encapsulamento das alças e por isto procedeu-se somente à peritoneostomia de cinco centímetros no quadrante superior direito do abdome, com evacuação de seis litros de material gelatinoso. A evolução foi favorável e com lavagens sucessivas o abdome diminuiu de volume e persistiu somente uma pequena drenagem, sempre coletada por bolsa de colostomia.

A doença é grave e não se deve fazer grandes ressecções, porque a cirurgia será sempre paliativa e a evolução desfavorável, ainda que lenta ${ }^{1}$. As reintervenções são freqüentes e os pacientes costumam evoluir com obstrução intestinal ${ }^{1,5}$. Nos casos em pauta, não parecia possível uma ressecção e o problema da drenagem era um desafio, porque qualquer tipo de dreno parecia ineficiente. A laparoscopia foi decisiva para o diagnóstico e a peritoneostomia foi a opção encontrada para a drenagem. Os pacientes não tiveram que ser reoperados de imediato, o que certamente acarretaria mais sofrimento e piora do estado geral.

\begin{abstract}
The authors report the surgical procedure in two patients with pseudomyxoma peritonei, histologically considered as mucinous adenocarcinoma. In both patients, intestinal loops and other visceras were blocked and it was not possible to localize the tumor's origin. There was, in both cases, a great volume of mucinous ascitis. In the first patient a laparotomy was performed and a drainage by a five centimeters peritoneostomy in the abdominal upper left quadrant. In the second just a peritoneostomy was performed in the same location. The sequential irrigation of the abdominal cavity controlled the ascitis in a few days. Certainly this approach avoided a second procedure to clean the mucinous ascitis.
\end{abstract}

Key Words: Pseudomyxoma peritonei; Mucinous adenocarcinoma; Peritoneostomy 


\section{REFERÊNCIAS}

1. Machado MACM, Rodrigues JG, Laurino Neto RM et al. Tratamento conservador de Pseudomixoma Peritoneal, Rev Hosp Clin Fac Med S Paulo 1993, 48:298301.

2. Cafiero F, Peressini A, Bertoglio S e al. Polimyxoma peritonei: a rare case. Anticancer Res 1997, 17:39013905.

3. Prayson RA, Hart WR, Petras RE. Pseudomyxoma peritonei. A clinicopathologic study of 19 cases with emphasis on site of origin and nature of associated ovarian tumors. Am J Pathol 1994, 18:591-603.

4. Elias D, Sabourin JC. Les pseudomyxomes péritonéaux. J Chir 1999, 136:341-347.
5. Nawaz A, Karakurum A, Weltman D et al. Pseudomyxoma Peritonei Manifesting as Intestinal Obstruction. South Med J 2000, 93: 891-893.

Endereço para correspondência:

Olívio Louro Costa

R. Horácio Andrade de Carvalho, 210 29052-620 - Vitória-ES

e-mail: olivio@terra.com.br 